\title{
Búsqueda de actividad inhibitoria de tripsina y elastasa en extractos de vegetales autóctonos
}

\author{
Search of inhibitory activity of trypsin \\ and elastase in extracts of native plants
}

\author{
Macció, Laura ${ }^{(1)}$, Vallés, Diego ${ }^{(1)}$, Cantera, Ana María ${ }^{(1,2)}$. \\ (1) Laboratorio de Enzimas Hidrolíticas, Facultad de Ciencias, Universidad de la República, UdelaR, Montevideo, Uruguay \\ (2) Cátedra de Bioquímica, Departamento de Biociencias, Facultad de Química, Universidad de la República, UdelaR, \\ Montevideo, Uruguay.
}

Contacto: acantera@fq.edu.uy

RECIBIDO: 17/6/2014 - APROBADO: 10/11/2014

\begin{abstract}
Resumen
Se estudió la capacidad inhibitoria para tripsina y elastasa de extractos de vegetales autóctonos: flores de Achyrocline satureioidehojas (marcela), hojas de Baccharis trimera (carqueja), frutos de Eugenia uniflora (pitanga) y frutos Schinus molle (anacahuita). Los extractos, que presentaron diferentes propiedades, se obtuvieron utilizando agua o etanol como solventes en distintas condiciones de tiempo y temperatura. La acción inhibitoria para elastasa fue baja $(<30 \%)$ o casi nula en los extractos ensayados. Para la tripsina, todos los extractos presentaron acción inhibitoria, observándose para un mismo material vegetal importantes diferencias según el solvente utilizado, independientemente de la temperatura de extracción. Los extractos de S. molle fueron los de mayor actividad inhibitoria para tripsina. Al extracto acuoso de este vegetal, obtenido a $100{ }^{\circ} \mathrm{C}$, se le determinó $\mathrm{IC}_{50} \mathrm{y}$ tipo de inhibición.

Palabras clave: Inhibidores proteolíticos, serin-proteasas, inhibidores vegetales.
\end{abstract}

\begin{abstract}
The inhibitory capacity of trypsin and elastase of extracts prepared from Achyrocline satureioidehojas flowers, Baccharis trimera leaves, Eugenia uniflora fruits and Schinus molle fruits was studied. The extracts showed differences for the same plant material depending on using water or ethanol as solvents, and were obtained under different time and temperature conditions. The elastase inhibitory action was low $(<30 \%)$ or almost absent in the extracts tested. For trypsin, all extracts showed inhibitory action and significant differences depending on solvent used, regardless of the extraction temperature. Extracts of S. molle showed the most potent inhibitory activity for trypsin. The aqueous extract of this plant obtained at $100^{\circ} \mathrm{C}$ was selected to determine $\mathrm{IC}_{50}$ and inhibition type. Keywords: Proteolytic inhibitors, serin-proteases, plant inhibitors.
\end{abstract}

\section{Introducción}

Las enzimas proteolíticas desempeñan un papel esencial en los procesos de regulación de funciones celulares, tanto en etapas del desarrollo como tras la respuesta ante un estímulo dañino (Fuster-Lluch, et al., 2004).

Las proteasas serínicas son la clase más estudiada de proteasas y la tripsina es utilizada como modelo para este grupo (Leung, et al., 2000).

Los inhibidores de proteasas, ampliamente distribuidos en todos los organismos, han sido aislados y caracterizados de plantas, animales y microorganismos (Mosolov, et al., 2001; Haq, et al., 2004; Christeller, 2005).

En las plantas, los inhibidores de proteasas son compuestos a los que se les ha atribuido importantes funciones biológicas, entre ellas, participación en los mecanismos de defensa, en la regulación de proteasas endógenas (Lawrence y Koundal, 2002, Lingaraju, et al., 2008) y en respuesta a diversos factores abióticos (Díaz, 2006; Mosolov y Valvuena, 2011). Se ha postulado que estos compuestos pueden brindar resistencia a plagas y fitopatógenos. Estos inhibidores también pueden ser utilizados como agentes terapéuticos, fármacos dirigidos o agentes nutracéuticos, y por esta razón su uso biotecnológico va en aumento (Tiffin y Gaut, 2001; Fei Fang, et al., 2010).

A diferencia de las proteasas, las familias de inhibidores no pueden ser agrupadas según el tipo catalítico de las enzimas que inhiben, porque algunas familias contienen inhibidores que actúan sobre distintas clases de proteasas (Rawlings, et al., 2004).

En el caso particular de la familia de inhibidores de proteasas serínicas, las más abundantes en plantas son: Bowman-Birk, Kunitz y Serpina, con características y modos de acción muy diferentes (Habib y Fazili, 2007).

Las flores de Achyrocline satureioidehojas (marcela), hojas de Baccharis trimera (carqueja), frutos frescos de Eugenia uniflora (pitanga) y frutos secos de Schinus molle (anacahuita) constituyen una fuente natural y renovable con posibilidad de aumentar el valor agregado de los productos obtenidos de la flora autóctona de Uruguay. Además, estos vegetales 
son utilizados generalmente por la medicina popular y en particular algunos son producidos en Uruguay como materia prima empleada en las industrias cosméticas y farmacéuticas.

El objetivo de este trabajo consistió en buscar la capacidad inhibitoria de proteasas en extractos de vegetales autóctonos de Uruguay y evaluar su acción frente a tripsina y elastasa.

\section{Materiales y Métodos}

\section{Materiales}

\section{Equipos}

Agitador magnético Caramag MIdi, balanza Gram Precision GX-230, baño de agua termostatizado Bioblock Scientific, centrífuga refrigerada Sigma 3K18, espectrofotómetro Shimadzu UV-1603.

\section{Reactivos}

Azocaseína, Na-benzoil-L-arginina etil ester (BAEE), succinil-ala-ala-ala p-nitroanilina (SucAla 3 -PNA), ácido tricloroácetico (TCA), hipoclorito de sodio, buffer fosfato de sodio. Todos ellos calidad ppa.

\section{Material vegetal}

Al tratarse de flora nativa y autóctona, todos los ejemplares fueron colectados en vías públicas. Las hojas de Achyrocline satureioidehojas (marcela) fueron colectadas en abril, las hojas de Baccharis trimera (carqueja) fueron colectadas a principios de verano, los frutos de Eugenia uniflora (pitanga) fueron colectados a fines de primavera y los frutos secos de Schinus molle fueron colectados en verano (Figura 1).

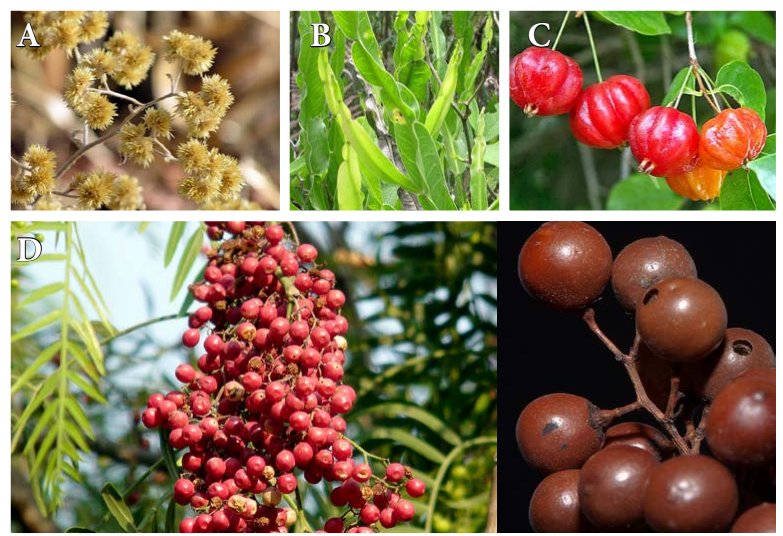

Figura 1. Material vegetal. a) Flores de Achyrocline satureioidehojas; b) Hojas de Baccharis trimera y Frutos de c) Eugenia uniflora d) y Schinus molle.

\section{Métodos}

\section{Preparación de extractos vegetales}

Los extractos vegetales fueron preparados a partir de material vegetal previamente desinfectado con solución de hipoclorito de sodio $(0,5 \% \mathrm{v} / \mathrm{v})$ durante 30 minutos a temperatura ambiente. Fueron enjuagados repetidas veces con agua destilada y finalmente secados en corriente de aire sobre papel de filtro.

\section{Extractos acuosos}

El material vegetal $(2,0 \mathrm{~g})$ se extrajo con $10,0 \mathrm{~mL}$ de agua destilada, se machacó en mortero y se agitó magnéticamente durante 5 minutos. El preparado se filtró a vacío por vidrio sinterizado, el filtrado obtenido se centrifugó durante 10 minutos a $6654 x g$ a $4{ }^{\circ} \mathrm{C}$. Se trabajó a dos temperaturas, 25 y $100^{\circ} \mathrm{C}$. Se fraccionó y almacenó a $-20^{\circ} \mathrm{C}$.

\section{Extractos etanólicos}

Se procedió de igual forma que para la preparación de extractos acuosos, empleando etanol como solvente para la extracción en dos condiciones de temperaturas: 25 y $40{ }^{\circ} \mathrm{C}$. Los extractos obtenidos se evaporaron en rotaevaporador a $45^{\circ} \mathrm{C}$. Luego de evaporado el alcohol, se resuspendió el concentrado con $10 \mathrm{~mL}$ de agua destilada. Se fraccionó y almacenó a $-20^{\circ} \mathrm{C}$

\section{Actividad proteolítica}

\section{Método de Azocaseína \\ (sustrato semi-sintético no específico)}

Se determinó la actividad proteolítica utilizando azocaseína como sustrato por método de Andrew \& Asenjo modificado (Vallés, et al., 2007).

Una unidad enzimática $\left(\mathrm{U}_{\mathrm{Azo}}\right)$ se define como la cantidad de enzima necesaria para producir el incremento en una unidad de absorbancia a $337 \mathrm{~nm}$ a $37^{\circ} \mathrm{C}, \mathrm{pH} 7,2$.

\section{Método de Na-Benzoyl-L-Arginine Ethyl Ester (BAEE) (sustrato sintético específico para tripsina)}

Se determinó la actividad proteolítica utilizando BAEE como sustrato según método descrito por Bergmeyer (1974).

Una unidad BAEE $\left(\mathrm{U}_{\mathrm{BAEE}}\right)$ se define como la cantidad de enzima que produce un $\Delta \mathrm{A}_{253 \mathrm{~nm}}$ de 0,001 por minuto utilizando BAEE como sustrato a $\mathrm{pH} 7,6,25^{\circ} \mathrm{C}$ en un volumen de reacción de $3,2 \mathrm{~mL}$.

\section{Método de Succinyl-ala-ala-ala p-nitroanilide (SucAla ${ }_{3}$-PNA) (sustrato sintético específico para elastasa)}

Se determinó la actividad proteolítica de elastasa utilizando SucAla $_{3}$-PNA (Bieth, et al., 1974).

Una unidad $\left(\mathrm{U}_{\text {SucAla3-PNA }}\right)$ queda definida como la cantidad de elastasa que hidroliza $1,0 \mu \mathrm{mol} \mathrm{SucAla}{ }_{3}$-PNA por minuto a pH 8,0 y $25^{\circ} \mathrm{C}$.

\section{Preparados enzimáticos}

Se prepararon soluciones de elastasa y de tripsina como soluciones enzimáticas patrón que se utilizaron para evaluar la capacidad inhibitoria de los extractos vegetales. 


\section{Obtención de elastasa a partir de polvo pancreático}

El preparado de elastasa se obtuvo por extracción de $1 \mathrm{~g}$ de polvo pancreático desgrasado con $20 \mathrm{~mL}$ de buffer fosfato de sodio $0,1 \mathrm{M}, \mathrm{pH}$ 6,0 con agitación durante 30 minutos. Se centrifugó a $6654 x g$, durante 15 minutos a $4^{\circ} \mathrm{C}$. El precipitado se trató de igual manera, combinando ambos sobrenadantes para obtener la solución final.

\section{Elastasa}

El preparado obtenido a partir de polvo pancreático fue diluido para obtener una solución de trabajo de 0,62 $\pm 0,05$ $\mathrm{U}_{\text {SucAla3-PNA }}$ en buffer Tris-HCl 0,1M, pH 8,0.

\section{Tripsina}

Todos los ensayos fueron realizados con una solución 3,2 \pm $0,2 \mathrm{U}_{\mathrm{Azo}} / \mathrm{mL}$ : buffer fosfato de sodio $0,2 \mathrm{M}, \mathrm{pH} 7,2$.

\section{Búsqueda de actividad inhibitoria en extractos vegetales}

Se mezcló $900 \mu \mathrm{L}$ de solución de tripsina o elastasa con 100 $\mu \mathrm{L}$ de cada extracto (diluido al tercio) durante 30 minutos en baño de agua a $37^{\circ} \mathrm{C}$.

Se determinó la actividad proteolítica empleando azocaseína como sustrato para tripsina y SucAla3-PNA para elastasa. Se determinó el \% de actividad inhibitoria (\%AI) como la diferencia de actividad de la enzima en ausencia de extracto inhibidor y la actividad de la enzima en presencia de extracto inhibidor.

\section{Caracterización de la actividad inhibitoria}

\section{Tiempo de incubación}

Se determinó el \%AI variando los tiempos de incubación (0, $5,10,20,30,45$ minutos) del preparado de tripsina con el extracto vegetal seleccionado.

\section{Determinación de $\mathrm{IC}_{50}$}

Se determinó la actividad proteolítica de tripsina, empleando azocaseína y BAEE como sustratos, y se calculó \% AI para las distintas concentraciones de los extractos seleccionados incubados durante 5 minutos con tripsina.

Se trazó diagrama de Dixon y se calculó el valor $\mathrm{IC}_{50}$.

\section{Determinación del tipo de inhibición}

Se incubó $900 \mu \mathrm{L}$ tripsina con distintos volúmenes de extracto $(0,6,0,10,0,20,0,40,0$ y $60,0 \mu \mathrm{L})$, ajustado a un volumen final de $1000 \mu \mathrm{L}$ con agua $\left(25^{\circ} \mathrm{C}, \mathrm{pH} 7,0\right)$. La mezcla se incubó durante 5 minutos a $25^{\circ} \mathrm{C}$.

\begin{tabular}{|c|c|c|c|c|c|}
\hline $\mathrm{N}^{\circ}$ & Material vegetal & Solvente & $\mathrm{T}\left({ }^{\circ} \mathrm{C}\right)$ & $\mathrm{pH}($ extracto $)$ & Apariencia física del extracto \\
\hline 1 & \multirow{4}{*}{$\begin{array}{l}\text { A. satureioidehojas } \\
\text { (flores) }\end{array}$} & \multirow[t]{2}{*}{ Agua } & 25 & 4,5 & Marrón claro \\
\hline 2 & & & 100 & 4,5 & Marrón oscuro \\
\hline 3 & & \multirow{2}{*}{ Etanol } & 25 & 4,5 & Amarillo verdoso \\
\hline 4 & & & 40 & 4,5 & Amarillo verdoso intenso \\
\hline \multirow{2}{*}{$\begin{array}{l}5 \\
6\end{array}$} & \multirow{4}{*}{ B. trimera (hojas) } & \multirow{2}{*}{ Agua } & 25 & 5,0 & Marrón oscuro \\
\hline & & & 100 & 5,0 & Marrón claro \\
\hline 7 & & \multirow{2}{*}{ Etanol } & 25 & 5,0 & Verde oscuro \\
\hline 8 & & & 40 & 5,0 & Verde fluorescente \\
\hline \multirow{2}{*}{$\begin{array}{c}9 \\
10\end{array}$} & \multirow{4}{*}{ E. uniflora (frutos) } & \multirow{2}{*}{ Agua } & 25 & 4,0 & Rosa pálido \\
\hline & & & 100 & 4,0 & Rosa bordeaux \\
\hline 11 & & \multirow{2}{*}{ Etanol } & 25 & 4,0 & Bordeaux \\
\hline 12 & & & 40 & 4,0 & Bordeaux \\
\hline 13 & \multirow{4}{*}{ S. molle (frutos) } & \multirow{2}{*}{ Agua } & 25 & 4,0 & Beige oscuro con precipitado \\
\hline 14 & & & 100 & 4,0 & Beige oscuro con precipitado \\
\hline 15 & & \multirow{2}{*}{ Etanol } & 25 & 4,0 & Beige anaranjado oscuro con precipitado \\
\hline 16 & & & 40 & 4,0 & Beige anaranjado con precipitado \\
\hline
\end{tabular}

Tabla 1. pH y color de los extractos. 
Se determinó la actividad de tripsina para distintas concentraciones de $\operatorname{BAEE}(0,05,0,0625,0,125,0,25,0,3$ y 0,5mM) para cada mezcla. Se trazó diagrama de Lineweaver-Burk y se determinó el tipo de inhibición.

\section{Resultados}

\section{Obtención de extractos vegetales}

Como resultado de las diferentes condiciones de extracción se obtuvieron 16 extractos para los vegetales ensayados. Para un mismo material vegetal se observaron diferencias en el color de los extractos debidas al solvente empleado. $\mathrm{El} \mathrm{pH}$ final de los extractos de un mismo vegetal tuvo el mismo valor, no variando con las distintas condiciones de extracción (Tabla 1).

\section{Búsqueda de actividad proteolítica}

A cada uno de los extractos se les determinó la actividad proteolítica a fin de descartar interferencias con posibles proteasas presentes en ellos. Los ensayos realizados para cada extracto no detectaron actividad proteolítica.

\section{Actividad inhibitoria}

La acción inhibitoria fue determinada por incubación de los extractos con cada una de las enzimas: tripsina y elastasa.

Las condiciones de obtención de los extractos y \% AI para tripsina y elastasa incubadas con los diferentes extractos se muestran en la Tabla 2.
Se observó que los preparados 3 y 4 obtenidos a partir de A. satureioidehojas presentaron $40 \%$ de inhibición de tripsina.

El extracto 6 alcanzó un $56 \%$ de inhibición de tripsina, siendo el de mayor grado inhibitorio de los preparados de B. trimera.

Los extractos 11 y 12 de E. uniflora alcanzaron 75 y $80 \%$ de inhibición de tripsina, y los extractos 9 y 10 obtenidos del mismo material vegetal mostraron un grado de inhibición de tan solo $16 \%$.

La acción inhibitoria de los extractos 15 y 16 de $S$. molle fue de 80 y $92 \%$ para tripsina. Los extractos 13 y 14 tuvieron una acción inhibitoria del 62 y $64 \%$.

La extracción en medio acuoso mostró una menor inhibición en la mayoría de los vegetales en comparación a la extracción etanólica, presentando E. uniflora la mayor diferencia $(60 \%)$. Esto podría deberse a la extracción diferencial ejercida por los solventes empleados, ya sea que se extraigan distintos fitoquímicos o diferentes concentraciones de los mismos.

Para la inhibición de elastasa se alcanzó el mayor grado de inhibición (24-28\%) con los extractos preparados a partir de E. uniflora (11 y 12) y $S$. molle (15 y 16). El resto de los extractos no mostraron inhibición de elastasa de significancia.

Se seleccionaron los extractos que presentaron para cada material vegetal una alta capacidad inhibitoria de tripsina y baja actividad para elastasa (extractos acuosos 6 y 14; extractos etanólicos 4 y 12).

\section{Efecto del tiempo de incubación en la actividad inhibitoria para tripsina}

Se estudió el efecto del tiempo de incubación sobre la capacidad inhibitoria de los extractos seleccionados a $37^{\circ} \mathrm{C}, \mathrm{pH} 7,2$.

\begin{tabular}{|c|c|c|c|c|c|c|c|}
\hline $\mathrm{N}^{\circ}$ & Material vegetal & Órgano & Solvente & $\mathrm{T}\left({ }^{\circ} \mathrm{C}\right)$ & $\mathrm{pH}$ (extracto) & $\% \mathrm{AI}_{\text {TRIPSINA }}$ & $\% \mathrm{AI}_{\text {ELASTASA }}$ \\
\hline 1 & \multirow{4}{*}{ A. satureioidehojas } & \multirow{4}{*}{ Flores } & \multirow{2}{*}{ Agua } & 25 & 4,5 & 23 & 11 \\
\hline 2 & & & & 100 & 4,5 & 24 & 7 \\
\hline 3 & & & \multirow{2}{*}{ Etanol } & 25 & 4,5 & 40 & 8 \\
\hline 4 & & & & 40 & 4,5 & 41 & 4 \\
\hline 5 & \multirow{4}{*}{ B. trimera } & \multirow{4}{*}{ Hojas } & \multirow{2}{*}{ Agua } & 25 & 5,0 & 38 & 4 \\
\hline 6 & & & & 100 & 5,0 & 56 & 8 \\
\hline 7 & & & \multirow{2}{*}{ Etanol } & 25 & 5,0 & 38 & 9 \\
\hline 8 & & & & 40 & 5,0 & 37 & 11 \\
\hline 9 & \multirow{4}{*}{ E. uniflora } & \multirow{4}{*}{ Frutos } & \multirow{2}{*}{ Agua } & 25 & 4,0 & 16 & 9 \\
\hline 10 & & & & 100 & 4,0 & 16 & 8 \\
\hline 11 & & & \multirow{2}{*}{ Etanol } & 25 & 4,0 & 75 & 24 \\
\hline 12 & & & & 40 & 4,0 & 79 & 28 \\
\hline 13 & \multirow{4}{*}{ S. molle } & \multirow{4}{*}{ Frutos } & \multirow{2}{*}{ Agua } & 25 & 4,0 & 62 & 13 \\
\hline 14 & & & & 100 & 4,0 & 64 & 9 \\
\hline 15 & & & \multirow{2}{*}{ Etanol } & 25 & 4,0 & 80 & 28 \\
\hline 16 & & & & 40 & 4,0 & 92 & 28 \\
\hline
\end{tabular}

Tabla 2. Condiciones de extracción (solventes y temperaturas) y \%AI de tripsina y elastasa de los extractos obtenidos a partir de Achyrocline satureioidehojas (1- 4), Baccharis trimera (5- 8), Eugenia uniflora (9-12) y Schinus molle (13-16). 
La actividad inhibitoria de los extractos no varió a lo largo de los tiempos de incubación ensayados (Gráfico 1).

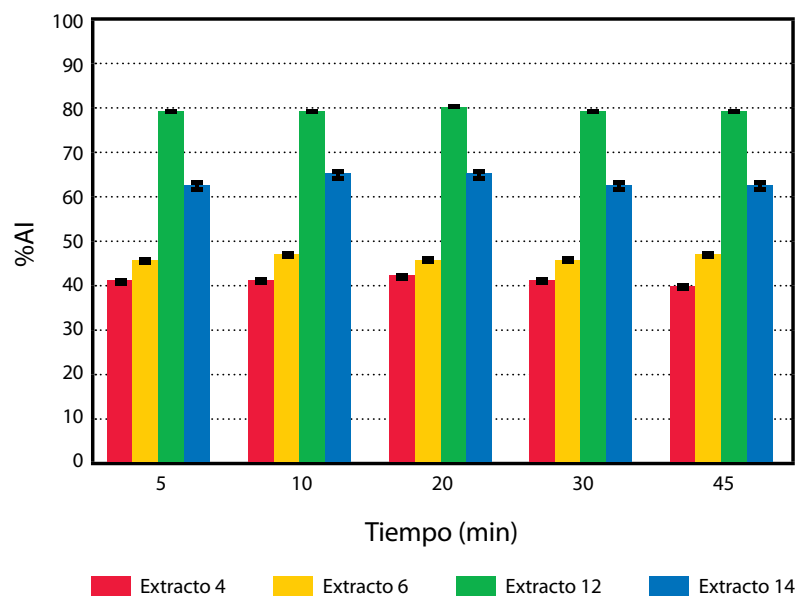

Gráfico 1. \%AI de tripsina vs tiempo de incubación para el extracto 4, 6, 12 y 14 .

Este resultado descartaría la acción de inhibidores irreversibles, los cuales se caracterizan por mostrar un continuo aumento de la actividad inhibitoria a lo largo del tiempo. En todos los casos se alcanzó el máximo de actividad inhibitoria a los 5 minutos.

\section{Determinación de $\mathrm{IC}_{50}$}

Se determinó la concentración de extracto vegetal que inhibe el $50 \%$ de la actividad de tripsina. Los valores de $\mathrm{IC}_{50}$ de las muestras seleccionadas se muestran en la Tabla 3.

\begin{tabular}{|c|c|c|c|c|}
\hline Extracto & Material vegetal & Solvente & $\mathrm{IC}_{50}(\mu \mathrm{L})$ & $\mathrm{IC}_{50}(\mathrm{mg} / \mathrm{mL})$ \\
\hline 2 & $\begin{array}{c}\text { A. } \\
\text { satureioidehojas } \\
\text { (flores) }\end{array}$ & agua & 2,4 & $2.0 \times 10^{-5}$ \\
6 & $\begin{array}{c}\text { B. trimera } \\
\text { (hojas) }\end{array}$ & etanol & 80 & $8.5 \times 10^{-4}$ \\
12 & $\begin{array}{c}\text { E. uniflora } \\
\text { (frutos) } \\
\text { S. molle } \\
\text { (frutos) }\end{array}$ & etanol & 40 & $1.1 \times 10^{-3}$ \\
\hline
\end{tabular}

Tabla 3. $\mathrm{IC}_{50}$ de los extractos 2, 6, 12 y 14 .

Los extractos acuosos de A. satureioidehojas y $S$. molle presentaron los mejores valores de $\mathrm{IC}_{50}$ frente a los extractos etanólicos estudiados.

Se seleccionó el extracto 14 para realizar la caracterización de la inhibición de tripsina, dado que presentó las mejores características para ser utilizado en aplicaciones biotecnológicas (disponibilidad del material vegetal, extracción en agua, mayor capacidad inhibitoria de tripsina).

En los Gráficos 2 y 3 se muestra la variación en la actividad $\left(\mathrm{V}_{0}\right)$ de tripsina con distintas concentraciones de extracto utilizando azocaseína y BAEE como sustrato. Se trazó el diagrama de Dixon en cada caso. Los valores de $\mathrm{IC}_{50}$ determinados para el extracto 14 fueron de $4.5 \times 10^{-4}$ y 2.7 $\mathrm{X} 10^{-4} \mathrm{mg} / \mathrm{mL}$, respectivamente.

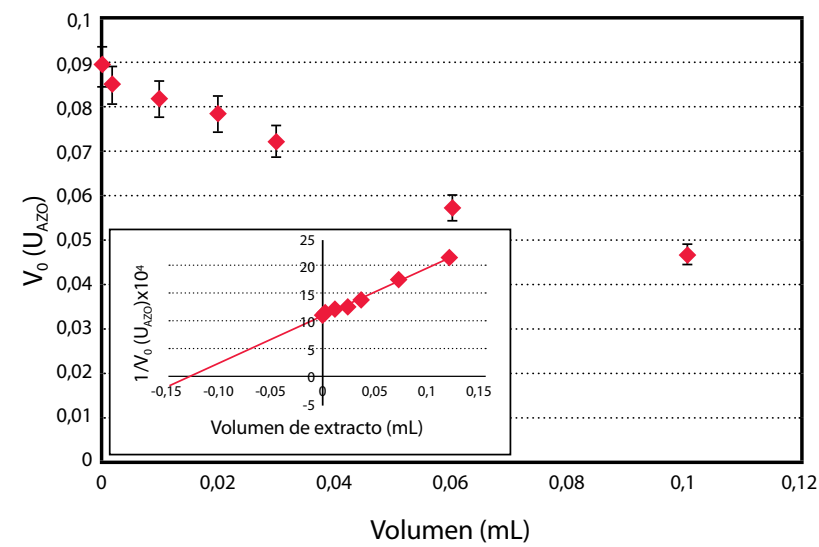

Gráfico 2. $\mathrm{V}_{0}$ de tripsina vs distintos volúmenes de extracto 14. Diagrama de Dixon.

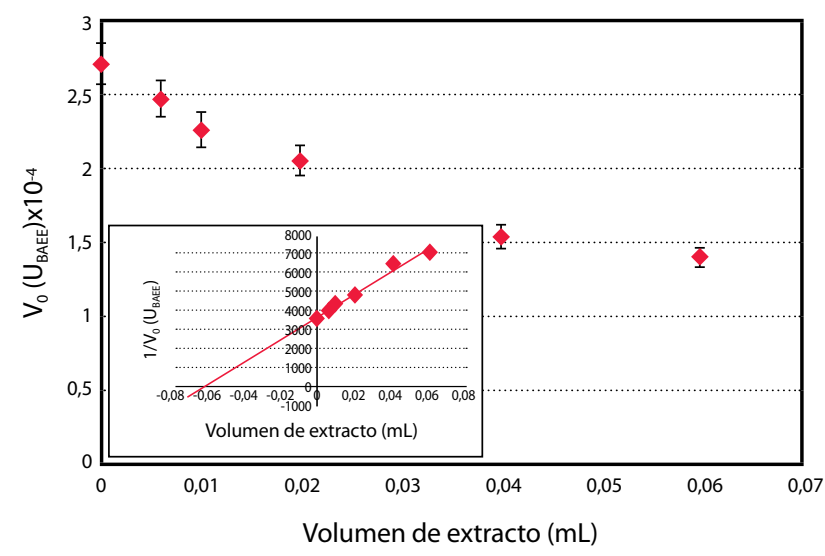

Gráfico 3. $\mathrm{V}_{0}$ de tripsina vs distintos volúmenes de extracto 14. Diagrama de Dixon.

\section{Determinación del tipo de inhibición}

Se trazó el Diagrama de Lineweaver-Burk para tripsina en ausencia de extracto inhibidor y con distintas concentraciones de extracto (Gráfico 4).

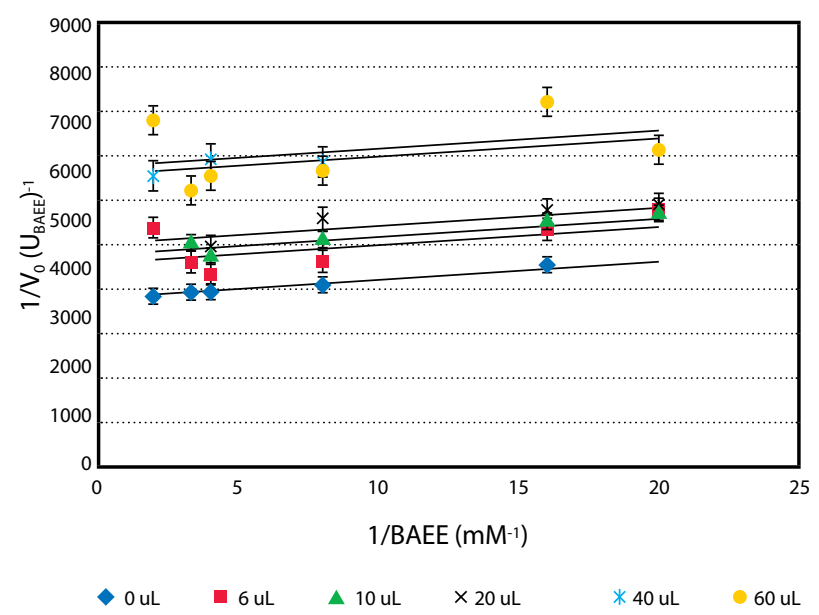

Gráfico 4. Diagrama de Lineweaver-Burk para tripsina inhibida con distintas cantidades de liofilizado de extracto 14 . 
El Gráfico 4 muestra un comportamiento típico de una inhibición acompetitiva para el extracto 14 . Al tratarse de una inhibición reversible, es esperable que la capacidad inhibitoria sea independiente del tiempo de inhibición una vez que se alcanza el equilibrio, como se puede observar en el Gráfico 1.

La adjudicación de este tipo de inhibición corresponde al comportamiento del extracto en su conjunto y no a los inhibidores aislados y purificados. Esto señala la necesidad de continuar con la purificación y tipificación de los inhibidores aislados en estudios futuros.

\section{Discusión}

A partir de cuatro vegetales autóctonos se obtuvieron extractos que presentaron diferentes propiedades con las condiciones de extracción. Las diferencias observadas en las propiedades de los distintos extractos podría deberse a la extracción diferencial de componentes químicos o a la diferente concentración de los mismos en cada extracto como resultado de la combinación de condiciones de extracción.

Todos los extractos vegetales estudiados presentaron actividad inhibitoria para tripsina y para elastasa, siendo de mayor relevancia la capacidad inhibitoria para tripsina. Frente a los resultados obtenidos, una potencial aplicación de estos extractos vegetales sería la acción como insecticidas naturales, lo cual les significaría un lugar en el mercado en la protección de cultivos. En particular los extractos acuosos, debido a que son amigables con el medio ambiente.

De los materiales vegetales evaluados, $S$. molle ha mostrado ser el más atractivo para producción de preparados de base natural con capacidad controladora de plagas que afectan a cultivos.

Según estudios anteriores, $S$. molle es una planta que presenta actividad antifúngica y antimicrobiana, principalmente en las hojas (Gundidza, 1993). Tiene importancia etnobotánica, pues se la ha utilizado en el control de plagas agrícolas en varias oportunidades (Iannacone y Lamos, 2003; Silva, et al., 2005). También fue evaluada la actividad insecticida de extractos de frutos de $S$. molle sobre larvas de Cydia pomonella (Chirino, et al., 2001). Si bien en el trabajo de Chirino (2001) la acción insecticida no fue adjudicada a ninguna familia de compuestos químicos, los inhibidores de proteasas serínicos podrían ser importantes candidatos a ser considerados como responsables de algunas de estas propiedades presentadas en $S$. molle. De acuerdo a los datos existentes, la mortalidad en insectos podría deberse específicamente a inhibidores de tripsina, lo cual provoca una disminución en la digestión en los animales patógenos, dificultando o inhibiendo su normal desarrollo.

\section{Conclusiones}

Todos los extractos presentaron potencial de actividad inhibitoria de tripsina pero solo algunos presentaron inhibición de elastasa. Fue seleccionado el extracto de S. molle obtenido en solvente acuoso a $100{ }^{\circ} \mathrm{C}$ para realizar la caracterización de la inhibición de tripsina. El IC50 del extracto inhibidor para tripsina utilizando el sustrato Azocaseína fue de $109 \mathrm{uL}$ y con BAEE como sustrato, de 63 uL. La acción inhibitoria del extracto presentó un comportamiento típico de una inhibición acompetitiva.

\section{Reconocimientos}

Este trabajo fue realizado en el marco de una beca de iniciación a la investigación financiada por la Agencia Nacional de Investigación e Innovación (ANII).

\section{Referencias}

Bergmeyer, H.U., 1974. Methods of enzymatic analysis. 2a ed. Vol. 1. Nueva York: Academic Press. pp.515-516.

Bieth, J., Spiess, B., Wermuth, C.G., 1974. The synthesis and analytical use of a highly sensitive and convenient substrate of elastasa. En: Biochem. Med., 11(4), pp.350-357.

Chirino, M., Cariac, M., Ferrero, A.A., 2001. Actividad insecticida de extractos crudos de drupas de Schinus molle L. (Anacardiaceae) sobre larvas neonatales de Cydia Pomonella L. (Lepidoptera: Tortricidae) En: Bol. San. Veg. Plagas, 27, pp.305-314.

Christeller, J.T., 2005. Evolutionary mechanisms acting on proteinase inhibitor variability. En: FEBS J., 272, pp.5710-5722.

Díaz, M.M., 2006. Proteasas digestivas de tipo tripsina del taladro del maíz, Sesamia nonagrioides (lepidoptera: noctuidae): caracterización e interacción con la proteína insecticida Cry1Ab [En línea]. Madrid: Universidad Politécnica de Madrid. (Tesis Doctoral). [Consulta noviembre de 2013]. Disponible en: http://oa.upm. es/453/1/MARIA_MERCEDES_DIAZ_MENDOZA.pdf

Fei Fang, E., Ho Wong, J., Fern Bah, C.S., Lin, P., Wah Tsao, S. y Bun Ng, T., 2010. Bauhinia variegata var. variegata trypsin inhibitor: From isolation to potential medicinal applications. En: Biochem. Biophys. Res. Commun., 396, pp.806-811.

Fuster-Lluch, O., Galindo, M.F., Ceña, V. y Jordán, J., 2004. Las serina proteasas y su función en los procesos de muerte neuronal. En: Rev. Neurolog, 38(5), pp.449-457.

Gundidza, M., 1993. Antimicrobial activity of essential oil from Schinus molle. En: Linn. Cent. Afric. J. Med., 39, pp.231-234.

Habib, H. y Fazili, K.M., 2007. Plant protease inhibitors: a defense strategy in plants. En: Biotech. Mol. Biol. Rev., 2(3), pp.68-85.

Haq, S.K., Atif, S.M. y Khan, R.H., 2004. Protein proteinase inhibitor genes in combat against insects, pests, and pathogens: natural and engineered phytoprotection. En: Arch. Biochem Bioph., 431, pp.145-159.

Iannacone, J., Lamas, G., 2003. Toxicological effects of Peruvian peppertree (Schinus molle) and lantana (Lantana camara) on Chrysoperla externa (Neuroptera: Chrysopidae), Trichogramma pintoi (Hymenoptera: Trichogrammatidae) and Capidosoma koehleri (hymenoptera: Encyrtidae) in Peru. En: Agricultura Técnica, 63(4), pp.347-360.

Lawrence, P.K. y Koundal, K.R., 2002. Plant protease inhibitors in control of phytophagous insects. En: Elec. J. Biotech., 5, pp.121-143.

Leung, D., Abbenante, G. y Fairlie, D.P., 2000. Protease inhibitors: current status and future prospects. En: J Med Chem., 43, pp.305-341.

Lingaraju, M.H. y Gowda, L.R., 2008. A Kunitz trypsin inhibitor of Entada scandens seeds: another member with single disulfide bridge. En: Biochem Biophys Acta, 1784(5), pp.850-855. 
Mosolov, V.V., Grigoryeva, L.I. y Valueva, T.A., 2001. Involvement of proteolytic enzymes and their inhibitors in plant protection (review). En: Appl. Biochem. Microbiol., 37(2), pp.115-123.

Mosolov, V.V. y Valueva, T.A., 2011. Inhibitors of proteolytic enzymes under abiotic stresses in plants (review). En: Appl. Biochem. and Microbiol., 47(5), pp.453-459.

Rawlings, N.D., Tolle, D.P. y Barrett, A.J., 2004. Evolutionary families of peptidase inhibitors. En: Biochem. J, 378, pp.705-716.
Silva, G., Orrego, O., Hepp R. y Tapia, M., 2005. Búsqueda de plantas con propiedades insecticidas para el control de Sitophilus zeamais en maíz almacenado. En: Pesq. Agropec. Bras., 40(1), pp.11-17.

Tiffin, P. y Gaut, B., 2001. Molecular evolution of the woundinduced serine protease inhibitor wip1 in zea and related genera. En: Mol. Bio. Evol., 18(11), pp.2092-2101.

Vallés, D., Furtado, S. y Cantera, A.M.B., 2007.

Characterization of news proteolytic enzymes from ripe fruits of Bromelia antiacantha Bertol. (Bromeliaceae). En: Enzyme Microb. Tech., 40, pp.409-413. 